\title{
UMA LEITURA DE DOM CASMURRO, \\ DE MACHADO DE ASSIS: \\ OS ESPAÇOS DO DOMINADOR: \\ A CASA DE MATACAVALOS \\ E A ESCRITA DE BENTO SANTIAGO
}

\author{
Leila Cristina Barros ${ }^{l}$ \\ Universidade Federal de Minas Gerais
}

"A alma humana é tão cheia de camadas como uma casa antiga."

Carl G. Jung

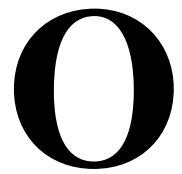

narrador Bento Santiago explica, no segundo capítulo de Dom Casmurro, o motivo que o levou a escrever seu livro: "restaurar na velhice a adolescência". Ele procura "atar as duas pontas da vida", está à procura do tempo perdido, mas confessa: "não consegui recompor o que fui (...)". Antes de escrever a obra, porém, "Dom Casmurro", como é chamado então, reproduz a casa de Matacavalos, onde viveu toda a sua infância. A finalidade é a mesma: reconstruir a própria vida. Poderíamos nos perguntar, no entanto, por que a reconstrução da casa serviria a esse propósito. Somente pelo fato de Bento ter passado ali a sua feliz infância? Creio que não seja só isso. O próprio Bento, em uma passagem do livro, dá-nos pistas de como interpretar a importância que tem o espaço da casa:

${ }^{1}$ Mestranda em Literatura Brasileira na FALE/UFMG. 
A alma da gente, como sabes, é uma casa assim disposta, não raro com janelas para todos os lados, muita luz e ar puro. Também as há fechadas e escuras, sem janelas, ou com poucas e gradeadas, à semelhança de conventos e prisões. ${ }^{2}$

Esses espaços abertos e fechados, e outros ainda, tais como alto, baixo, passagens, são recorrentes na obra e nos permitem relacioná-los com outro importante espaço, que é o das relações sociais entre as personagens.

A casa de Bentinho em Matacavalos era o espaço do dominador - no caso, dominadora - que é a matriarca da família Santiago, Dona Glória, a quem todos devotavam obediência e evitavam contrariar: o irmão Cosme, a prima Justina, o agregado José Dias, o filho Bentinho, enfim, todos os que a rodeavam. Essa subordinação a Dona Glória é evidenciada pela recorrência na narrativa da expressão "ao pé de":

Capitu vivia ao pé dela. (p.78)

(...) se Bentinho não estiver ao pé de mim. (p.100)

Ajoelhei-me ao pé do leito (...) (p.101)

(...) o retrato de Escobar (...) ao pé do de minha mãe (...) (p.158)

Veremos adiante que essa expressão também aparece diversas vezes para referir-se à casa.

Além de sua própria figura de mulher superior e dominadora, a casa de Dona Glória ficava em uma posição de superioridade em relação à casa do pai de Capitu, por exemplo: Bentinho, quando criança, "descia" a chácara e passava ao quintal vizinho. E isso não é por acaso, como nos faz crer a leitura do ensaio "Espaço e Espaços":

Tomando como exemplo a oposição alto/baixo, podemos observar que ela não se limita ao âmbito geográfico, mas revela uma série de concepções ideológicas presentes nas produções simbólicas da

${ }^{2}$ ASSIS, 1994, p.87. A partir desta, todas as citações retiradas desta obra serão seguidas dos números das páginas em que se encontram). 
sociedade; prende-se à idéia religiosa de céu e inferno, à divisão de classes sociais [grifo meu], a conceitos morais (...) $)^{3}$

Também situa-se no alto a casa da Glória, onde Bento foi morar depois de casado; ela fica no Alto da Tijuca, e há várias referências a "descer":

(...) falávamos em descer (...) (p.138)

(...) Capitu estava um tanto impaciente por descer. (p.138)

(...) José Dias (...) foi a única pessoa cá de baixo que nos visitou na Tijuca. (p.139)

A altura é "símbolo de ascensão e de espiritualização, de assimilação progressiva àquilo que o céu representa: uma harmonia nas alturas.” " Na casa da Glória há escadas, que são também “(...) o símbolo por excelência da ascensão e da valorização(...)" Paradoxalmente, porém, não é harmoniosa a vida de Bentinho nessa casa "das alturas": é justamente aí que começa a sua decaída espiritual ao inferno do ciúme. Lembremo-nos de que, logo na primeira semana de casados, Bentinho desconfia de Capitu, que, segundo ele, "estava um tanto impaciente para descer." (p.138) A casa da Glória, enfim, ao contrário do que o nome possa sugerir, não lhe reservaria muitas glórias.

Como vimos, em oposição à casa de Matacavalos e à da Glória está a de Pádua, homem de origem humilde e que devia favores a Dona Glória; também era assobradada como a da família de Bento, porém menor. Além disso, ficava "ao pé" da outra e geralmente é referida como "a casa vizinha", "a casa ao pé". Dona Fortunata, mãe de Capitu, aparece diversas vezes no quintal, na porta dos fundos. Sua casa, muito pobre, é assim descrita:

\footnotetext{
${ }^{3}$ WALTY \& MENDES, 1985, p.87.

${ }^{4}$ CHEVALIER \& GHEERBRANT, 1994, p.40.

${ }^{5}$ CHEVALIER \& GHEERBRANT, 1994, p.378.
} 
(...) era um espelhinho de pataca (perdoai a barateza), comprado a um mascate italiano, moldura tosca, argolinha de latão (...) (p.54)

(...) eu fitava (...) o chão, o roído das fendas, duas moscas andando e um pé de cadeira lascado (p.70)

No muro que dividia as casas de Capitu e Bentinho havia uma abertura que servia de ligação entre elas, mas era utilizada apenas pelas crianças, que foram criadas "quase como irmãs" (grifo meu). Essa "porta" não servia aos adultos.

Segundo Chevalier e Gheerbrant, em seu Dicionário de Símbolos, a porta "(...) não somente indica uma passagem, mas convida a atravessá-la. (...) simboliza o local de passagem entre dois estados, entre dois mundos, entre o conhecido e o desconhecido, a luz e as trevas, o tesouro e a pobreza extrema." 6 (grifos meus) As crianças eram criadas "quase" como iguais, para elas não havia diferenças de classes, que só seriam sentidas e colocadas à mostra pelo autor depois de adultos.

José Dias, por sua vez, pelo fato de ser "um simples agregado" (palavras de Bentinho) da família Santiago, um homem sem posses, que vivia de favores, "teve o seu quarto ao fundo da chácara". Outro espaço, portanto, em posição de inferioridade em relação à casa de Dona Glória. Prima Justina, apesar de ser da mesma classe social de Dona Glória, segundo o próprio Bentinho "(...) vivia conosco por favor de minha mãe, e também por interesse." (p.41) No centro e no alto, portanto, estão as casas dos senhores da classe dominante, e na periferia (no fundo, ao pé) estão as outras.

Perdido o espaço físico de outrora, Bento tenta resgatá-lo através da reconstituição da casa de Matacavalos, sua "primeira construção", revelando assim uma busca, justificada pelo fato de a casa ser "(...) um símbolo feminino, com o sentido de refúgio, de mãe, de proteção, de seio maternal." 7 Dom Casmurro tenta no

${ }^{6}$ CHEVALIER \& GHEERBRANT, 1994, p.734.

${ }^{7}$ CHEVALIER \& GHEERBRANT, 1994, p.196. 
presente a reconstrução de sua vida passada, mas não consegue; ele se apega à memória daqueles que o guiavam, que não mais existem. Devemos nos lembrar de que ele sempre foi guiado por outras pessoas: por duas mulheres (sua mãe e Capitu) e por dois homens de posição social inferior à sua (Escobar e José Dias).

Na verdade, ele sempre viveu de aparências, e a reconstituição da casa de Matacavalos reforça isso, já que, segundo Chevalier e Gheerbrant, "o exterior da casa é a máscara ou aparência do homem." Sua vida atual é uma representação: ele compara as visitas femininas que recebe em sua vida de homem maduro a uma exposição, "após a qual as mulheres não levam nada mais do que frias listas de quadros, em vez de afetos e sentimentos pessoais":? "(...) e também esta cansava, e ia embora com o catálogo na mão..." (p.183)

O Bento atual perdeu seu espaço e sua identidade, que é a da sua classe. Ele foi Bentinho, depois Doutor Bento de Albuquerque Santiago e, finalmente, o "Dom Casmurro", que não detém mais os poderes de sua classe, mas um título de "Dom", que veio como "ironia", para dar-lhe "ares de fidalgo". Onde está, afinal, sua supremacia? Além de seu prestígio, ele perdeu as pessoas mais próximas, talvez as únicas que o amaram um dia: a mãe, a esposa, o filho, o melhor amigo, o tio, a prima, o empregado - apesar de tudo - fiel.

A mulher e o filho, ele próprio encarregou-se de banir de sua vida. Ainda pequeno, Ezequiel foi levado a um colégio interno: "(...) levei-o a pé, pela mão, como levara o ataúde do outro." (p.169) A crueldade aumenta quando passa por sua cabeça doentia fazê-lo ingerir uma xícara de café com veneno. Mais tarde, Bento consegue o seu intento, levando mãe e filho para a Suíça e deixando-os lá até a morte de Capitu e o regresso de Ezequiel. Este fato reaviva em sua

${ }^{8}$ CHEVALIER \& GHEERBRANT, 1994, p.196.

9 PAIXÃO, 1994, p.183. 
mente a lembrança de Escobar e da suposta traição de sua mulher, mas não por muito tempo, afinal seu filho (?) morre meses depois, para seu alívio: “(...) pagaria o triplo para não tornar a vê-lo.” (p.182)

Por que Bento quer agora, depois de perder sua família e amigo, reconstituir "os tempos idos"? Recorramos novamente a Chevalier e Gheerbrant: "A morte designa o fim absoluto de qualquer coisa de positivo: um ser humano, (...) uma amizade, uma aliança, a paz (...) não se fala na morte de uma tempestade, mas na morte de um dia belo." ${ }^{10}$ Talvez Bento tenha finalmente se dado conta de que perdeu sua paz e os momentos realmente felizes de sua vida. Ele próprio dá-nos pistas disso:

Para quem chegou, como eu, a arrenegar deste casamento, era duro confessar que ele foi uma verdadeira bênção do céu. (p.154)

Que era preciso para viver? Nunca mais deixar aquela casa (...) (p.170)

No último exemplo, percebemos seu apego à casa. A primeira tentativa de reconstruir sua vida - exatamente com a reconstituição da casa de Matacavalos - foi, porém, sem êxito; então, dedicou-se à escrita do livro: sua "segunda construção".

O narrador perde o espaço de domínio e só o reconquista ao escrever o livro, onde sua voz é a única que se faz imprimir; ele fala por si e pelos outros personagens: domina o espaço, as pessoas e, conseqüentemente, sua fala. Na obra, ele pode manter a arrogância e o poder de sua classe.

Narrando o livro em primeira pessoa, Bento pôde expor o seu ponto de vista, aliás somente ele, e aí está o problema: não conhecemos a versão de Capitu ou qualquer outra pessoa envolvida, apenas a de um homem ciumento e passional.

Sempre mantendo essa superioridade, Bento jamais admitiu que suas suspeitas com relação a Capitu pudessem estar erradas; seus objetivos, ao escrever o livro, são de incriminar sua esposa e

${ }^{10}$ CHEVALIER \& GHEERBRANT, 1994, p.621. 
se autojustificar. De fato, “(...) formado em Direito, Bentinho é um advogado e sua narrativa uma longa peça judiciária, num processo crime, em que ele funciona como advogado de acusação." ${ }^{11}$

Ao mesmo tempo que corre o "processo de acusação" contra Capitu, Bento prepara, com muita habilidade, o "processo de defesa" de si próprio: tenta manter sua condição de vítima, de "bom moço" que é sempre conduzido por outras pessoas e traído pela esposa e pelo melhor amigo.

Apesar de todas as tentativas de se autojustificar e de reconstruir sua vida, ele fracassa e acaba se sentindo sozinho. Tenta dissimular sua atual condição, dizendo que "(...) vida diferente não quer dizer vida pior; é outra coisa.”, (p.14) mas acaba confessando seu vazio interior: "um homem consola-se mais ou menos das pessoas que perde, mas falto eu mesmo e esta lacuna é tudo." (p.14)

No final da narrativa, percebemos por que realmente Bento Santiago recebeu o apelido de Dom Casmurro: “(...) o verdadeiro significado da palavra é o que também lhe é dado: o de homem aborrecido, enjoado, ranzinza, solitário, ensimesmado, desconfiado."12 Finalmente, este homem deixa transparecer toda a sua desilusão e amargura: "Ó ruas antigas! Ó casas antigas! Ó pernas antigas! Todos nós éramos antigos, e não é preciso dizer que no mau sentido, no sentido de velho e acabado." (p.155)

Bento sente-se "velho e acabado" - "no mau sentido" - e esse fato pode ser explicado, afinal, ele falha duas vezes ao tentar "atar as duas pontas da vida": falha na reconstrução do espaço físico da casa de Matacavalos e falha na construção de um outro espaço, que é o seu livro. Tanto o espaço da casa quanto o espaço do livro, como vimos, servem ao dominador Bento Santiago, que, no entanto, não consegue suprir sua falta, não consegue preencher o espaço vazio dentro de si próprio.

${ }^{11}$ COUTINHO, 1995, p.253.

${ }^{12}$ COUTINHO, 1995, p.249. 


\section{Referências Bibliográficas}

ASSIS, Machado de. Dom Casmurro. 28.ed. São Paulo: Ática, 1994.

CHEVALIER, Jean, GHEERBRANT, Alain. Dicionário de símbolos. 8.ed. Rio de Janeiro: José Olympio, 1994.

COUTINHO, Afrânio. Estudo introdutivo e notas. In: ASSIS, Machado de. Dom Casmurro. São Paulo: Ediouro/PUBLIFOLHA, 1995.

PAIXÃO, Fernando. Nota do editor. In: ASSIS, Machado de. Dom Casmurro. 28.ed. São Paulo: Ática, 1994.

WALTY, Ivete Lara Camargos, MENDES, Nancy Maria. Espaço e Espaços. Ensaios de Semiótica, Belo Horizonte, n.14, p.87.

\section{Resumo}

Neste trabalho, busco a análise e a articulação de dois espaços em "Dom Casmurro": a casa de Matacavalos e o livro de Bento Santiago, ambos vistos como lugares em que se impõe a voz do dominador.

\section{Abstract}

This work is an attempt to analyse and articulate with each other two entities in "Dom Casmurro": Matacavalos house and Bento Santiago's book, both of them seen as environments marked by the presence of a dominant voice. 